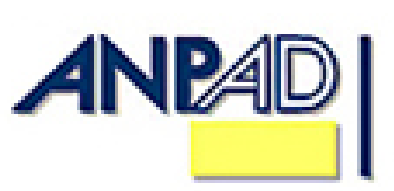

Disponível em

http://www.anpad.org.br/rac

RAC, Curitiba, v. 14, n. 4

pp. 738-743, Jul./Ago. 2010

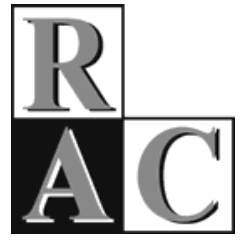

Documentos e Debates:

\title{
Réplica 1 - Por uma maior (e melhor) Integração das Perspectivas Teóricas do Pensamento Estratégico
}

\author{
For more (and better) Integration of Strategic Management Theories
}

Sandro Cabral *

Doutor em Administração pela UFBA.

Professor Adjunto da UFBA, Salvador/BA, Brasil.

Sérgio G. Lazzarini

PhD em Administração pela John M. Olin School of Business, Washington University.

Professor do Insper, São Paulo/SP, Brasil.

*Endereço: Sandro Cabral

Av. Reitor Miguel Calmon, s/n, $3^{\circ}$ andar, Vale do Canela, Salvador/BA, 40110-903. Email: scabral@ufba.br

Copyright (C 2010 RAC. Todos os direitos, inclusive de tradução, são reservados. É permitido citar parte de artigos sem autorização prévia desde que seja identificada a fonte. 
Com muita satisfação realizamos a réplica ao artigo de Gláucia Maria Vasconcellos Vale e Humberto Elias Garcia Lopes, em resposta ao convite formulado pelos Professores Rogério Quintella e Jaime Fensterseifer. À primeira vista, o termo réplica pode suscitar a idéia de contestação ou oposição à linha de argumentação apresentada. Em verdade, porém, intentamos aprofundar o debate iniciado pelos autores em seu manuscrito, aportando elementos adicionais que possam engendrar reflexões à comunidade científica debruçada sobre o campo da Estratégia em Organizações.

Grosso modo, os autores buscam realizar o mapeamento das diversas correntes teóricas que podem ser invocadas no estudo de alianças e estratégias colaborativas. Intentam também demonstrar como as diferentes perspectivas teóricas se articulam entre si, muito embora não haja maior elaboração no artigo em termos de integração teórica. Sem entrar no mérito da consecução, ou não, dos objetivos propostos, fundamentalmente centramos nossa argumentação nas interconexões das diferentes teorias, justamente por acreditarmos que aí reside o elemento que possibilita maior fôlego explicativo e analítico dos construtos da área de Estratégia. Nosso principal ponto é que acadêmicos têm subestimado possibilidades de integração teórica, por superestimarem as incompatibilidades entre teorias alternativas. Antes, porém, fazemos breve menção aos aspectos relativos à classificação das linhas do pensamento estratégico.

\section{A Dor e a Delícia de Mapear o Campo}

Parte significativa das áreas do conhecimento é marcada por apresentar um caráter multifacetado e polissêmico. Com influência marcante da Sociologia, da Psicologia e da Economia, em suas mais diversas vertentes, a área de Estratégia não foge à regra. Tamanha diversidade, não raro, faz com que os pesquisadores frequentemente envidem esforços no intuito de mapear a miríade de correntes que compõem um dado corpo teórico. Via de regra, tal empreitada exige trabalho hercúleo que se inicia com a delimitação do recorte a ser estudado, passa pela escolha dos veículos a serem analisados, culminando na leitura de dezenas, centenas de artigos científicos, não necessariamente nessa ordem, bem entendido. Na qualidade de pesquisadores, acreditamos que essa é a fonte de motivação intelectual do acadêmico. É ali que nós - e alguns dos que nos leem nesse momento - encontramos uma fonte inexorável de prazer e autorealização, na medida em que, ao nos embrenharmos na mata da pesquisa bibliográfica, podemos ter a oportunidade de rever nossas posições, além de sorver o conhecimento produzido por outros, ora discordando, ora concordando, ora aprimorando quanto a certas linhas de raciocínio. Lamentamos profundamente que as outras demandas relacionadas ao mundo acadêmico, sobretudo os afazeres administrativos, nos impeçam de dedicar maior parte de nosso tempo ao exame profundo, e por certo interminável, das referências que nos interessam. Os autores, ao realizarem esse honesto levantamento bibliográfico, ao que aparenta, conseguiram desvencilhar-se dos grilhões da roda-vida que insiste em nos aprisionar.

Por sua vez, o esforço de classificação das correntes de um determinado campo exige bastante rigor, na medida em que, além de avaliar quais são as reais contribuições analíticas da área candidata a fazer parte do seleto grupo de correntes que compõem o corpo de conhecimento mais amplo, é preciso ter com muita clareza alguns fatores que realmente distinguem tais aportes das demais abordagens. Dentre estes figuram: unidade de análise, pressupostos e dimensões analíticas. É evidente que as escolhas empreendidas implicam renúncias, sendo praticamente impossível não exercer o poder discricionário, sob pena de perder os matizes que separam cada corpo teórico. Sucede que se tais escolhas não forem consistentemente embasadas e tratadas, dentro do rigor que se espera no meio científico, inevitavelmente questionamentos emergirão. Corre-se o risco, nesse caso, de tipificar corpos teóricos que poderiam ser perfeitamente encapsulados por outras correntes ou ainda de omitir alguma vertente relevante.

Há, no entanto, outros pequenos pecados muito comuns que podem ocorrer em trabalhos que buscam compreender as correntes teóricas que circundam determinadas áreas do conhecimento. Assim, não é incomum que pesquisadores, ao tentarem discorrer sobre determinado campo, acabem por optar pela mera descrição de pontos de amplo conhecimento sem o necessário aprofundamento em questões ainda abertas dentro do próprio corpo de conhecimento. Com efeito, mesmo em correntes 
teóricas supostamente consolidadas, é frequente a existência de ramificações, dissensões e discordâncias entre os seus próprios filiados. A explicitação e a compreensão das diferenças existentes no seio do corpo teórico em tela fazem-se necessárias, sob pena de o retrato sair simplificado e reduzido.

\section{Sentar-se à Mesa para Poder Integrar}

Dito isso, compatibilizar num mesmo espaço corpos teóricos aparentemente distintos, na busca de instrumental analítico que permita elucidar fenômenos organizacionais, está longe de ser tarefa trivial. Em que pesem as dificuldades inerentes, alguns conseguem realizar as devidas conciliações teóricas com mestria. Nessa linha, Gibbons (2005a) tipifica quatro vertentes da multifacetada teoria da firma, buscando similaridades e distinções. Partindo de argumentos informais para a formalização dos pressupostos de cada teoria, o autor fornece os elementos necessários para um quadro de referência integrativo capaz de tratar diversos problemas teóricos e empíricos, aí incluídas as questões ligadas a alianças, joint-ventures, integração vertical e horizontal. Acreditamos que tal integração é extremamente benéfica para a área de estratégia, na medida em que as complementaridades existentes entre as diferentes correntes são fundamentais para compreender questões ainda a serem elucidadas.

É evidente que o diálogo entre diferentes correntes requer que pontes sejam construídas e que barreiras erguidas por adeptos de uma ou outra abordagem sejam quebradas. De fato, frequentemente observamos nos debates acadêmicos uma espécie de briga de torcidas, na qual a afirmação de um campo - e a tentativa de legitimidade dos pesquisadores imbuídos em sua consolidação - se dá em detrimento do rebaixamento e da desqualificação de outra corrente; dando contornos a uma discussão dicotômica tão profícua quanto uma contenda travada entre dois torcedores fanáticos sentados à mesa de um bar, cada um tentando convencer o outro que sua equipe é melhor e que o rival é pior. A radicalização ideológica nos meios acadêmicos, infelizmente, tem rechaçado muitas tentativas de integração, não raro, no escopo de manter uma linhagem pura de pesquisa, e que, ao que aparenta, não é suficiente para responder às grandes questões do pensamento estratégico.

Tomemos, por exemplo, o seguinte comentário dos autores sobre possíveis incompatibilidades teóricas:

Algumas teorias são incompatíveis entre si e dificilmente poderiam ser conjugadas em investigações empíricas. É o caso, por exemplo, da teoria das redes sociais com a teoria dos custos de transação. Os pressupostos de racionalidade restrita, presentes nesta última, seriam, à primeira vista, incompatíveis com proposições presentes na primeira, que consideram que as estruturas sociais influenciam as decisões empresariais. A teoria das redes sociais também apresenta certas incompatibilidades com abordagens presentes na teoria dos jogos (Vale \& Lopes, Documento, pp. 732-733).

Tomamos a liberdade de discordar desta afirmação. É fato que, na época em que o texto seminal de Granovetter (1985) foi escrito, havia um debate emergente sobre custos de transação; neste mesmo ano, Williamson publicaria um de seus principais livros, The Economic Institutions of Capitalism (Williamson, 1985). Deliberadamente, Granovetter quis estabelecer-se como contraponto à crescente literatura de Economia Organizacional. Porém, como a evolução posterior da literatura claramente demonstrou, considerações sobre o efeito de relações sociais não são incompatíveis com a abordagem de custos de transação. O próprio Williamson, em artigo publicado na revista Administrative Science Quarterly (Williamson, 1991), admitiu que o efeito de confiança e relações sociais pode agir como um parâmetro de mudança: ou seja, algo que pode reduzir custos de transação e possibilitar ganhos de troca. Esta idéia foi modelada empiricamente no artigo recente de Gulati e Nickerson (2008).

Mais recentemente, uma extensa literatura sobre as interações dos contratos formais com a governança relacional mostrou o grande ganho explicativo de articular conjuntamente as literaturas sociológicas e de custos de transação que se debruçavam sobre a questão das alianças empresariais. Poppo e Zenger (2002), de forma pioneira, mostraram que contratos não servem apenas para controlar problemas de oportunismo, como estabelecia Williamson; podem, outrossim, estabelecer parâmetros 
iniciais de negociação que conduzem ao estabelecimento de relações sociais duradouras, em apoio de uma transação. Da mesma forma, relacionamentos sociais não servem apenas para gerar confiança e outros aspectos informais da transação; podem também servir para refinar termos explícitos de contratos e, com isso, tornar a aliança mais previsível e gerenciável (ver, também, Mayer e Argyres, 2004).

O mesmo pode ser dito com respeito à teoria de redes sociais e teoria dos jogos. Inúmeros autores desta última corrente têm mostrado como diversos dilemas sociais (incluindo o famoso dilema dos prisioneiros) podem ser solucionados por meio de relações duradouras. Já existem modelos econômicos que mostram como interações repetidas podem permitir o uso de estratégias sociais de disseminação de informações sobre trocas passadas e gerar contextos onde o desempenho de uma transação (ou aliança) específica pode depender do contexto social onde está inserta - exatamente na linha discutida por Granovetter. Exemplos de estudos nesta linha incluem Kranton (1996) e Greif, Milgrom e Weingast (1994). O mundo de trocas atomizadas descrito por Granovetter (1985) para caracterizar a Teoria Econômica mainstream já é algo do passado. Não somente vários modelos econômicos passam a incorporar elementos anteriormente estranhos como falhas de racionalidade, normais sociais, decisões coletivas etc., como, também, vários economistas já passam a olhar de forma mais séria as contribuições que emergem em outras disciplinas, incluindo Psicologia, Sociologia e Ciências Políticas. Por exemplo, uma edição especial da prestigiosa revista Journal of Economic Perspectives foi inteiramente dedicada ao potencial de integração entre Economia Organizacional e Sociologia Econômica (ver Gibbons, 2005b).

Para evitar o risco do fechamento do debate em silos ou torcidas opostas, é preciso que nós, acadêmicos, procuremos entender as contribuições de teorias distintas (incluindo as mais recentes) e ter disposição para o diálogo. A nossa tendência, entretanto, é nós mesmos nos rotularmos: especialista em custos de transação, em teoria institucional, em redes sociais, visão baseada em recursos etc. E, estando especializados em áreas particulares, rapidamente perdemos noção dos avanços em outras áreas. Talvez seja este um dos problemas de integração do qual o nosso campo padece: pensamos em teorias, ao invés de pensarmos em problemas fundamentais ou questões de pesquisa ancoradas em fenômenos reais. Talvez seja mais fácil sentar à mesa para integrar diferentes abordagens, se partirmos de um interesse comum, algo que merece ser mais bem explicado ou compreendido, para só depois usarmos as ferramentas que cada um tem às mãos.

\section{À Busca de Relevância}

Durante a sessão plenária da área de Estratégia em Organizações no encontro da ANPAD em 2009, a palestrante internacional convidada, Professora Anita McGahan da Universidade de Toronto, mostrou ao público presente duas fotos: uma dos membros da equipe do Presidente dos Estados Unidos Barack Obama e outra dos líderes do G8, confortavelmente reunidos em Davos. Em seguida, a Professora Anita proferiu a seguinte questão provocativa: 'Quem dessas pessoas é ligada à área de Administração?' A resposta foi: 'nenhuma delas'. Possivelmente, a mesma resposta seria dada se a pergunta fosse feita com relação aos formuladores de políticas públicas no Brasil.

Um dos motivos alegados para a ausência de administradores ao redor das mesas de decisão é relacionado à escassez de discussões acadêmicas sobre como abordagens teóricas de Administração, e de Estratégia em particular, podem ser engajadas para responder a questões prementes de ordem social. Se o foco de Estratégia é explicar fontes de desempenho sustentável no longo prazo, por que não colocar foco em dimensões de desempenho que tenham elevada importância para o desenvolvimento econômico e social de forma mais ampla? Por exemplo, da mesma forma que se pode discutir como recursos e competências explicam vantagens competitivas de firmas, é possível analisar como escolhas estratégicas afetam a competitividade de regiões e outras variáveis de interesse coletivo. Michael Porter (1990), no seu celebrado livro The Competitive Advantage of Nations, mostrou que ferramentas de Estratégia também podem ser usadas por governantes e formuladores de políticas públicas; porém, desde então, a nossa área avançou apenas pouco mais que isso. 
Neste sentido, sentimos falta, no artigo dos autores, de uma discussão sobre alianças e redes colaborativas entre entes públicos e privados, que cada vez mais assumem importância tanto no dia-adia das políticas e discussões governamentais, quanto na conformação das próprias estratégias empresariais. Considere, por exemplo, a organização de serviços prisionais - tema no qual trabalhamos recentemente (ver Cabral, Lazzarini, \& Azevedo, no prelo). O desempenho de um sistema prisional envolve não apenas variáveis econômicas, como o custo das operações, mas também indicadores qualitativos difíceis de serem medidos, incluindo aí o nível de assistência médica aos presos, o uso de força por carcereiros, a qualidade das refeições etc. Vertentes teóricas de Economia Organizacional diriam que qualquer contrato com um operador privado (terceirizado) seria problemático pela impossibilidade de medir estes indicadores de qualidade com precisão. Por exemplo, ao se contratar um agente terceirizado como operador da prisão por um preço fixo por preso, este agente pode reduzir custos em detrimento de iniciativas que garantam alta qualidade do serviço.

Uma alternativa para resolver este dilema é criar um mecanismo híbrido, envolvendo um supervisor público dentro da prisão para monitorar as ações do agente privado. Porém, o que garantirá que este monitoramento ocorrerá a contento? O agente privado pode, eventualmente, subornar o supervisor público para que nenhum desvio seja reportado. Será preciso, então, discutir que incentivos implícitos o supervisor público terá para não se engajar neste esquema corrupto. Deverá o governo buscar burocratas weberianos guiados por normas e códigos de conduta bem explicitados? Pode o governo, alternativamente, induzir um efeito reputacional na relação com o burocrata? Por exemplo, criar uma carreira de longo prazo, bem definida e sanções críveis, caso ocorra falha de monitoramento? Qual o papel de entidades externas de monitoramento, como a mídia e organizações não-governamentais estabelecidas na forma de redes sociais de pressão? Estas questões também se aplicam em diversos arranjos público-privados, que envolvem objetivos sociais mais amplos, e difíceis de serem medidos, atrelados a contextos que envolvem múltiplos "principais" (isto é, grupos diversos que se beneficiam dos serviços prestados). Não há como uma única abordagem teórica, sozinha, explicar fenômeno tão complexo e multifacetado.

Fundamentalmente, nosso ponto é: problemas relevantes e complexos, como os acima mencionados, demandam o uso de múltiplas abordagens teóricas. Nessa linha, alguns trabalhos dentro dessa perspectiva já podem ser observados. Mahoney, McGahan e Pitelis (2009) tecem intricada teia sobre as inter-relações público-privadas nos negócios por meio da combinação de diversas teorias do pensamento estratégico. De Figueiredo (2009), em seu turno, combina os construtos de Estratégia com os das teorias positivas das Ciências Políticas, para discorrer sobre as non-market strategies utilizadas pelas organizações no intuito de ganhar vantagens competitivas por meio da interação com instituições políticas. Peng, Sun, Pinkham e Chen (2009) mostram como aspectos institucionais podem e devem ser incorporados no arsenal teórico do acadêmico de Estratégia.

Assim, em que pese a importância de conhecermos as diferentes perspectivas teóricas do pensamento estratégico, como fazem com competência os autores do artigo, acreditamos que a obtenção de boas respostas para boas perguntas passa pela capacidade de integração das diferentes teorias que permeiam o campo; o que, além da identificação de questões relevantes, requer o espírito desarmado para que possamos dialogar com diferentes correntes, quiçá integrando-as aos nossos referenciais de base. Naturalmente, para tal é necessário que estejamos continuamente em atualização a respeito dos avanços de nossos pares e abrindo nossas mentes para abordagens alternativas que, à primeira vista, podem parecer conflitantes. Estamos prontos para aceitar esse desafio?

\section{REFERÊNCIAS BIBLIOGRÁFICAS}

Cabral, S., Lazzarini, S. G., \& Azevedo, P. F. (no prelo). Private operation with public supervision: Evidence of hybrid modes of governance in prisons. Public Choice. 
De Figueiredo, J. (2009). Integrated political strategy. Advances in Strategic Management, 26, 459486.

Gibbons, R. (2005a). Four fomal(izable) theories of the firm?. Journal of Economic Behavior \& Organization, 58(2), 200-245,

Gibbons, R. (2005b). What is economic sociology and should any economists care? Journal of Economic Perspectives, 19(1), 3-7.

Granovetter, M. (1985). Economic action and social structure: the problem of embeddedness. American Journal of Sociology, 91(3), 481-510.

Greif, A., Milgrom, P., \& Weingast, B. (1994). Coordination, commitment and enforcement: the case of the merchant gild. The Journal of Political Economy, 102(4), 745-776.

Gulati, R., \& Nickerson, J. A. (2008). Interorganizational trust, governance choice, and exchange performance. Organization Science, 19(5), 688-708.

Kranton, R. E. (1996). Reciprocal exchange: a self-sustaining system. American Economic Review, 86(4), 830-851.

Mahoney, J., McGahan, A., \& Pitelis, C. (2009). The interdependence of public and private interests. Organization Science, 20(6), 1034-1052.

Mayer, K. J., \& Argyres, N. S. (2004). Learning to contract: evidence from the personal computer industry. Organization Science, 15(4), 394-410.

Peng, M., Sun, S., Pinkham, B., \& Chen, H. (2009). The institution-based view as a third leg for a strategy tripod. Academy of Management Perspectives, 23(3), 63-81.

Poppo, L., \& Todd, R. Z. (2002). Do formal contracts and relational governance function as substitutes or complements? Strategic Management Journal, 23(8), 707-726.

Porter, M. (1990). The competitive advantage of nations. New York: The Free Press.

Williamson, O. E. (1985). The economic institutions of capitalism. New York: The Free Press.

Williamson, O. E. (1991). Comparative economic organization: the analysis of discrete structural alternatives. Administrative Science Quarterly, 36(2), 269-296. 